\title{
CONSTIPATION IN CHILDREN
}

\author{
KHASINA
}

\section{Introduction:}

Constipation is a very common presentation, both in primary and secondary care. Considerable variation in 'normal' bowel habit in children is accepted. ${ }^{1} \mathrm{~A}$ normal pattern of stool evacuation is thought to be a sign of health in children of all ages. Especially during the first months of life, parents pay close attention to the frequency and the characteristics of their children's defecation. Any deviation from what is thought by any family member to be normal for children may trigger a call to the nurse or a visit to the pediatrician. Stool frequency is also agedependent. ${ }^{1}$ Infants have a mean of 4 stools per day during the first week of life. ${ }^{2}$ It reduces progressively in early childhood, from more than four stools a day to a mean average of 1.7 stools per day at 2 years of age and 1.2 a day at age 4 years, ${ }^{2,3}$ by which age $98 \%$ of children are toilet trained. ${ }^{4}$ Some normal breast-fed babies do not have stools for several days or longer. ${ }^{5}$ After 4 years, the frequency of bowel movements remains unchanged. ${ }^{5}$ The normal frequency of bowel movements at different ages has been defined (Table 1). ${ }^{6}$

Constipation is defined as a stool frequency of less than three per week with associated symptoms such as pain or overflow soiling or stool retention with or without soiling even the stool frequency is three per week or more. ${ }^{1}$ The child may be unable to have a bowel movement after straining or pushing for more than 10 minutes (Figure $1 \& 2){ }^{4}$ In most cases the parents are worried that the child's stools are too large, too hard, painful, or too infrequent. Constipation in children usually is functional and the result of stool retention. ${ }^{6}$ However, family physicians must be alert

Correspondence to : Dr. Kaniz Hasina, Associate Professor, Department of Pediatric Surgery, Dhaka Medical College \& Hospital E-mail : kanizhasina@gmail.com for the presence of an uncommon but serious organic cause of constipation. ${ }^{6}$ Constipation accounts for approximately $3 \%$ of general pediatric outpatient visits, about $25 \%$ of a pediatric gastroenterologist's work and is one of the 10 most common problems seen by general pediatricians. ${ }^{4,7}$

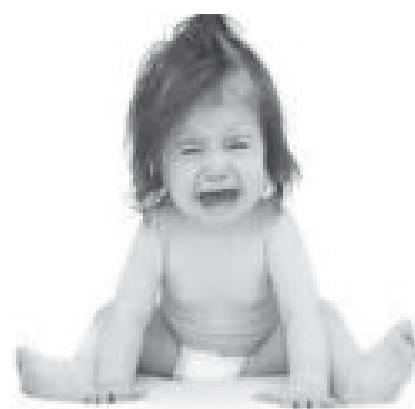

Figure 1

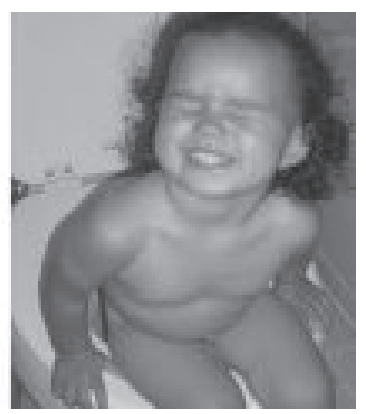

Figure 2
Table-I

Normal Frequency of Bowel Movements in Infants and Children

\begin{tabular}{lcc}
\hline Age & $\begin{array}{c}\text { Mean number of } \\
\text { bowel movements } \\
\text { per week }^{\text {a }}\end{array}$ & $\begin{array}{c}\text { Mean number of } \\
\text { bowel movements } \\
\text { per day }^{\mathrm{b}}\end{array}$ \\
\hline $\begin{array}{l}\text { 0 to 3 months: } \\
\text { breastfed }\end{array}$ & 5 to 40 & 2.9 \\
$\begin{array}{l}\text { 0 to 3 months: } \\
\text { formula-fed }\end{array}$ & 5 to 28 & 2.0 \\
6 to 12 months & 5 to 28 & 1.8 \\
$\begin{array}{l}\text { 1 to 3 years } \\
\text { More than 3 years }\end{array}$ & 4 to 21 & 1.4 \\
\hline
\end{tabular}

Adapted from Fontana M, Bianchi C, Cataldo F, Conti Nibali $\mathrm{S}$, CucchiaraS, Gobio Casali L, et al. Bowel frequency in healthy children. Acta Paediatr Scand 1989;78:682-4, with information from reference 8 . 


\section{Types of Constipation:}

- Functional constipation

- Acute constipation

- Chronic constipation

\section{Functional constipation}

It is the most common form of constipation in children, not associated with any congenital abnormalities, acquired diseases, or medications. Prevalence ranges from $4-36 \%$. ${ }^{9-11}$ The exact causes of constipation remain obscene. It may be due to a change in diet and fluid intake, during toilet training, by avoidance of bowel movement because of pain such as irritation, rash, fissure in anus. Treatment of functional constipation involves disimpaction using oral or rectal medication. ${ }^{6}$ Polyethylene glycol is effective and well tolerated, but a number of alternatives are available. After disimpaction, a maintenance program may be required for months to years because relapse of functional constipation is common. ${ }^{6}$ Maintenance medications include mineral oil, lactulose, milk of magnesia, polyethylene glycol powder, and sorbitol. Education of the family is instrumental in improving functional constipation. ${ }^{6}$ Behavioral education improves response to treatment. Cow's milk may promote constipation in some children, a trial of withholding milk may be considered. Adding fiber to the diet may improve constipation. Despite treatment, only 50 to 70 percent of children with functional constipation demonstrate long-term improvement. (Am Fam Physician 2006;73:469-77, 479-80, 481-2. Copyright (c) 2006 American Academy of Family Physicians.)

\section{Acute constipation}

It is more common at 6 months of age, may be associated with changes in diet, changes of environment, secondary to inactivity, due to anal fissure, after surgery, after measles and chicken pox infection. Acute abdominal pain, extension of legs and squeezing child's anal and buttock muscles prevent passage of stool. Treatment varies with age:

- In infants and toddlers- restriction of cow's milk intake, adding more water to the diet, laxatives e.g. senna or paraffin to soften the stool, enemas or suppositories are useful to clear the initial hard stool

- In older children- relieved by single enema, dietary manipulation by adding fibre like vegetables, fruits, fruit juices and fluid, plenty of water intake, laxatives until precipitating factor corrected

- In order child with acute anal fissure- stool softener, bulk laxatives, dietary modification, Sitz bath, glycerine trinitrate ointment, anal dilatation under $\mathrm{G} / \mathrm{A}$ and rarely surgery

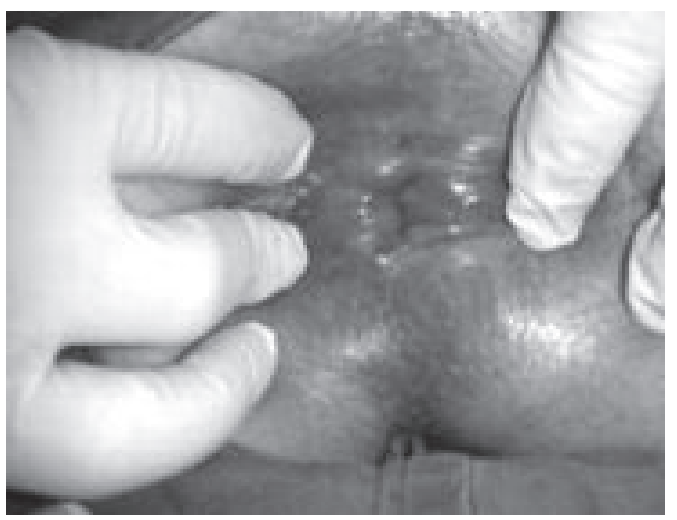

Figure 3: Anal fissure

\section{Chronic constipation}

Persistent constipation that does not rapidly respond to dietary manipulation or simple laxative treatment can be defined as chronic constipation. A child with chronic constipation can present with faecal soiling or pseudo incontinence in up to $90 \% .{ }^{12}$ It usually develops between the ages 2 and 4 years, one fourth of the patients having onset during first year of life. Children with chronic constipation and overflow soiling have no toilet training in $40 \%$ cases $^{1}$ and more than $30 \%$ are associated with enuresis. ${ }^{1}$

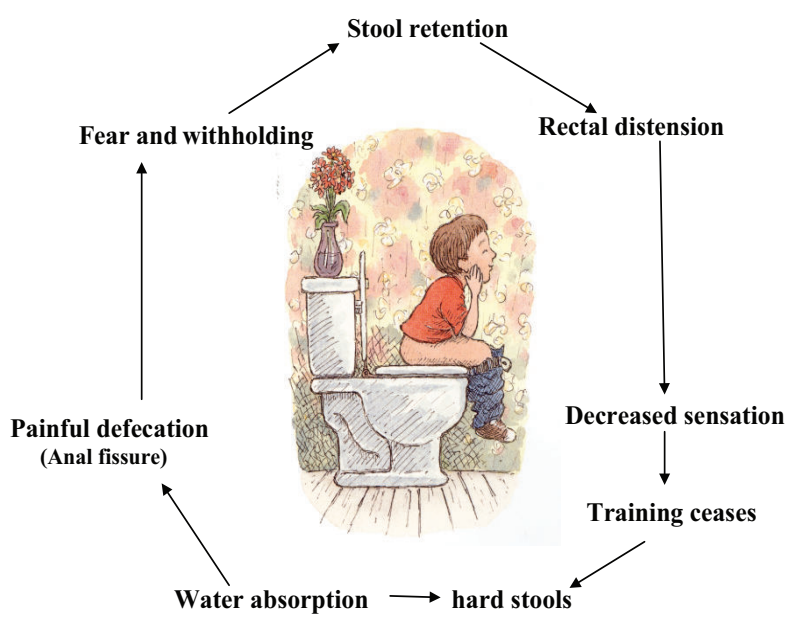

Figure 4

\section{Organic causes}

Organic causes of constipation most commonly are found in neonates (Table-II). ${ }^{8}$ Failure to pass a meconium stool within 48 hours of birth should raise suspicion for Hirschsprung's disease. In neonates, it is important to confirm the anatomic position and patency of the anus. The absence of an anal wink or a cremasteric reflex, the presence of a pilonidal dimple or hair tuft, or a decrease in lower extremity tone, strength, or reflexes may suggest a spinal cord abnormality such as tethered cord, myelomeningocele, or spinal cord tumor. 


\section{Aetiology of Chronic Constipation:}

Table-II

Differential Diagnosis of Constipation by Age*

\begin{tabular}{ll}
\hline Infants & Children (older than 1 year) \\
\hline Hirschsprung's disease & Functional constipation (>95\% of cases) \\
Congenital anorectal & Organic causes: \\
$\quad$ Malformations & Hirschsprung's disease \\
Neurologic disorders & Metabolic causes: hypothyroidism, \\
Encephalopathy & hypercalcemia, hypokalemia, \\
Spinal cord abnormalities: & diabetes insipidus, diabetes \\
myelomeningocele, spina & mellitus \\
bifida, tethered cord & Cystic fibrosis \\
Cystic fibrosis & Gluten enteropathy \\
Metabolic causes: & Spinal cord trauma or abnormalities \\
hypothyroidism, & Neurofibromatosis \\
hypercalcemia, hypokalemia, & Heavy-metal poisoning \\
diabetes insipidus & Medication side effects \\
Heavy-metal poisoning & Developmental delays \\
Medication side effects & Sexual abuse \\
\hline
\end{tabular}

*_Diagnoses listed by frequency. Information from reference 8.

\section{Diagnosis}

Depends on-

- History

- Physical examination

- Laboratory investigations

\section{Investigations}

- Plain x-ray abdomen in erect posture including both dome of diaphragm A-P view

- Barium enema x-ray without bowel preparation

- Thyroid function test specially TSH

- Serum calcium level

- Rectal biopsy

- Anorectal manometry

- X-ray of L/S spine lateral view \& MRI in case of neurological deficit

- Transit time study

- Defecogrophy

\section{Management}

The management of a child with chronic constipation includes-

- Parental counselling- It is the first step of management
- Disimpaction of fecaloma- It is contraindicated in a child with anal fissure

- Sustain complete evacuation- This includes dietary intervention, laxatives and behavioural modification

- Treatment of anatomic or metabolic or other definite cause

Behavioural therapy

- Varies with the age of the patient

- Infants and toddlers has no role

- Too early and too aggressive toilet training is discouraged

- Younger than 2 to 3 years toilet training should be avoided, Diapers reinstituted

- Older children encouraged to regular toilet routine after a major meal

\section{Conclusion:}

Constipation remains a prevalent problem, which can have a huge impact on children's quality of life, and places a burden on primary and secondary care. It is difficult to treat, and the relapse rate is high. With increased patient and parental understanding and support, as well as improving toileting habit, increasing fiber and optimizing laxatives; the potential exists to 
deliver a significant benefit to children, and revolutionize what can otherwise be an intractable and distressing condition. If a child's symptoms do not improve after six months of good adherence to a treatment regimen, referral to a pediatric gastroenterologist may be warranted. ${ }^{13}$

\section{References:}

1. Afzal AN, Mark PT, Mike AT. Constipation in children. Italian Journal of Pediatrics 2011, 37:28.

2. Nyhan WE. Stool frequency of normal infants in the first weeks of life. Pediatrics 1952; 10:41425.

3. Weaver LT, Steiner $\mathrm{H}$. The bowel habits of young children. Arch Dis Child 1983; 59:649-52.

4. Greg R, Anne D. Chronic Constipation in children. BMJ 2006, 333: 1051-55.

5. Hyams JS, Treem WR, Etienne NL, et al. Effect of infant formula on stool characteristics of young infants. Pediatr 1995; 95:50-4.

6. Wendy S. Biggs, M.D. and William H. Dery, M.D. Evaluation and Treatment of Constipation in Infants and Children. American Academy of Family Physicians 2006, 469-77.

7. Molnar D, Taitz LS, Urwin OM, Wales JK. Anorectal manometry results in defecation disorders. Arch Dis Child 1983; 58: 257-61.
8. Baker SS, Liptak GS, Colletti RB, Croffie JM, Di Lorenzo C, Ector W, et al. Constipation in infants and children: evaluation and treatment. A medical position statement of the North American Society for Pediatric Gastroenterology and Nutrition (published correction appears in J Pediatr Gastroenterol Nutr 2000; 30:109). J Pediatr Gastroenterol Nutr 1999; 29:612-26.

9. van der Wal MF, Benninga MA, Hirasing RA. The prevalence of encopresis a in a multicultural population. J Pediatr Gastroenterol Nutr 2005, 40:345-348.

10. de Araujo Sant'Anna AM, Calcado AC. Constipation in school-aged children at public schools in Rio de Janeiro, Brazil. J Pediatr Gastroenterol Nutr 1999, 29:190-193.

11. Yong D, Beattie RM. Normal bowel habit and prevalence of constipation in primary-school children. Ambulatory Child Health 1998, 4: 277-282.

12. Loening-Baucke V: Prevalence rates for constipation and faecal and urinary incontinence. Arch Dis Child 2007, 92:486-489.

13. McGrath ML, Mellon MW, Murphy L. Empirically supported treatments in pediatric psychology: constipation and encopresis. J Pediatr Psychol 2000; 25:225-54. 